\title{
Contracampo
}

\section{O som implicado: ruídos como experiência material do filme}

\section{The implicated sound: noise as a material experience of film}

\section{José Cláudio Siqueira Castanheira jcscastanheira@gmail.com}

Doutor em Comunicação pela Universidade Federal Fluminense (UFF). Professor e coordenador do Curso de Cinema da Universidade Federal de Santa Catarina (UFSC). Pesquisador na área de Estudos do Som, Cinema e Música.

É um dos autores do livro Reverberations: the philosophy, aesthetics and politics of noise (2012), editado por Michael Goddard, Benjamin Halligan e Paul Hegarty, e do livro Small cinemas in global markets: genres, identities, narratives (2015), editado por Lenuta Giukin, Janina Falkowska e David Nasser. Atua também como compositor de trilhas sonoras e sound designer para filmes.

Ao citar este artigo, utilize a seguinte referência bibliográfica

CASTANHEIRA, José Cláudio Siqueira. O som implicado: ruídos como experiência material do filme. In: Revista Contracampo, v. 33, n. 2 , ed. ago-nov, ano 2015. Niterói: Contracampo, 2015. Págs: 21-43.

DOI: 10.5327/Z22382577201500332737

Enviado em: 14 de mar. de 2015

Aceito em: 15 de jul. de 2015

\section{PPGCOM}

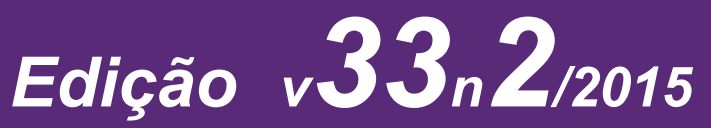

Comunicação e Materialidades 2

Contracampo

e-ISSN 2238-2577

Niterói (RJ), v. 33, n. 2, ago-nov/2015

www. uff.br/contracampo

A Revista Contracampo é uma revista eletrônica do Programa de PósGraduação em Comunicação da Universidade Federal Fluminense e tem como objetivo contribuir para a reflexão crítica em torno do campo midiático, atuando como espaço de circulação da pesquisa e do pensamento acadêmico. 


\section{Resumo}

Abordagem comum aos estudos estruturalistas, a necessidade de atribuir determinados sons a determinadas fontes ignora a materialidade dos objetos sonoros e sua capacidade de produzir efeitos para além das esferas da linguagem. Este trabalho propõe uma investigação sobre essas diferentes formas de perceber o filme enquanto matéria audível. $\mathrm{O}$ som, tomado como produtor de presença, pode oferecer uma noção menos limitada da experiência cinematográfica.

Palavras-chave: materialidades; som; ruído; cinema; tecnologias.

\section{Abstract}

Common approach to structuralist studies, the need to assign certain sounds to specific sources ignores the materialities of sound objects and their ability to produce effects beyond the sphere of language. This paper proposes an investigation on these different ways of perceiving the film as audible matter. Sound, taken as presence producer, can offer a less limited notion of cinematic experience.

Keywords: materialities; sound; noise; cinema; technologies. 


\section{Introdução}

clássica divisão do som fílmico em diálogos, música e ruídos nos apresenta uma
questão de significação. Abordagem cara aos estudos estruturalistas, a necessidade de atribuir determinados sons a determinadas fontes ignora a materialidade dos objetos sonoros e sua capacidade de produzir efeitos para além das esferas da linguagem. Alguns tipos de sons transcendem ou mesmo questionam a ideia de representação de objetos ou eventos por meios sonoros. Entre eles podemos citar o ruído, em suas diferentes formas; o silêncio, elemento não menos plural; e os sons das próprias tecnologias. Estes últimos carregam a assinatura sonora dos diferentes modelos de produção, histórica e culturalmente determinados. A análise fílmica tradicional — baseada em práticas interpretativas e na busca de sentidos ocultos sob a forma do filme - ignora, comumente, essas dimensões do som. O cinema, analisado como texto, não permite um recorte tão particular e, ao mesmo tempo, limita novas abordagens teóricas. No caso específico do ruído - visto como algo que dificulta os mecanismos representacionais através de interferências e distrações notamos como as tecnologias de gravação e edição perpetuam um discurso que se funda na erradicação de qualquer elemento sonoro que não permita um nível mínimo de inteligibilidade. Algumas questões mais gerais, como a oposição entre analógico e digital — como se o primeiro fosse o modelo mais propício à produção de ruído e o segundo representasse uma instância de maior pureza, melhor relação entre sinal e ruído e maior proximidade com o objeto original - , são frutos desse discurso. No caso das tecnologias de som (isso pode, claro, se estender às imagens) e o modo como, a partir delas, constroem-se novos modos de ouvir o filme, podemos perceber como essa assinatura sonora vem mudando com o tempo. Obviamente contaminada por outros movimentos da cultura contemporânea, vemos estabelecer-se certa inaudibilidade nos filmes atuais. Um "silêncio dos alto-falantes", como diz Chion (2009). Não ouvimos mais a base material do filme. Em contrapartida, a audibilidade de modelos mais antigos reveste-se de uma nostalgia que atribui a determinados ruídos uma capacidade de trazer de volta o passado.

Partindo de hipóteses apresentadas por Andy Birtwistle (2010), este artigo propõe uma investigação sobre essas diferentes formas de perceber o filme enquanto matéria audível, para além de parâmetros exclusivamente representacionais. A ideia, por Aden Evens (2005), de ruído de fundo enquanto movimento entrópico de reverberações em busca de equilíbrio 
e, ao mesmo tempo, modificador do evento sonoro, dotando-o de maior expressividade, nos ajuda em nossa pesquisa. Por fim, as descrições de culturas de presença e de sentido, como propostas por Gumbrecht, demonstram diferentes formas de relacionamento com o mundo, possibilitando uma noção menos limitada da experiência cinematográfica.

\section{Som como entropia}

Para Evens (2005), um corpo sensível é capaz de captar as diversas variações de pressão do ar e sintetizá-las como som percebido. Apesar das diferentes variáveis em ação - frequências fundamentais e sobretons, amplitude, formato, ataque, decaimento, entre outras características determinantes do timbre - , o som é percebido como evento único que se "contrai", destacando-se de um fundo de múltiplas ondas em eterno processo de entropia. Os sons perdem energia, tornam-se esparsos, fundem-se cada vez mais ao ambiente, porém persistem. O ato de contração é provocado por qualquer evento que dote determinado grupo de frequências de potência suficiente para, a partir dos sons aparentemente imóveis, conseguir reiniciar um movimento de organização e novamente dispersão. Esse é um processo de vir à tona e novamente submergir que não cessa: "Todo som mascara uma história inteira de sons, uma cacofonia do silêncio" (EVENS, 2005, p. 14).

Esse fundo indistinto e confuso é o que Evens chama de ruído. A percepção atribui sentido ao som "contraído", enquanto o ruído é o sem sentido, o não percebido. Porém, o ruído é também a base sem a qual não pode haver som. É a partir dele que aqueles elementos aos quais se pode atribuir algum significado são construídos.

Essa proposição é muito próxima da teoria termodinâmica dos corpos que Henri Atlan toma como base para a sua tese de auto-organização dos organismos. O ruído é necessário para a eterna atualização dos sistemas, colocando em xeque sua própria natureza: "O ruído provocado no sistema pelos fatores aleatórios do ambiente não seria mais um ruído verdadeiro a partir do momento em que fosse utilizado pelo sistema como fator de organização" (ATLAN, 1979, p. 56). Para Evens, há uma qualidade explícita no som percebido - destacado de seu fundo - e outra implícita no conjunto de sons que permanecem inaudíveis, mas que conformam todo som ouvido. Esse fundo é obscuro, mas responsável pela expressão do som explicado. A expressividade seria, então, uma ética 
da implicação. Seria deixar o som à deriva entre a claridade e o ruído. A transição entre as duas esferas será sempre imprevisível, tornando cada experiência única. A dimensão implicada do som é específica da performance, do ao vivo, do evento em transcurso. Há uma negociação constante entre o audível e o inaudível.

O digital, como modelo de privilégio do sinal, esforça-se para excluir o ruído. Os elementos de menor resolução são deixados de fora, tornando a experiência do som gravado digitalmente carente dos elementos fortuitos e expressivos - o que o sistema analógico aceitaria de forma mais complacente. E aqui devemos fazer uma diferenciação entre o ruído gerado no ato de gravação, em que o funcionamento digital sem partes móveis favoreceria um descarte de tudo que não fosse sinal, e o ruído gerado no ato de reprodução, incluindo aí os efeitos provenientes dos circuitos eletrônicos de amplificadores, caixas etc.

É claro que, em alguma medida, no próprio ato de transdução da onda sonora por captadores, microfones ou afins, há algum tipo de transformação ou filtragem de um material sonoro que se tornou explicado em relação ao contexto implicado. O implicado do registro sonoro não é só o disperso no ambiente, mas também o horizonte possível de variações elétricas do sistema. Em que medida isso vai ser traduzido em um fundo implicado, nós saberemos apenas quando da reprodução. O implicado eletricamente não reverbera, não molda o explicado enquanto apenas forma de registro. Também nesse sentido, tanto a gravação digital quanto a analógica apresentam perdas de referências implícitas. As partes móveis do sistema analógico fornecem outro contexto implicado que só é conhecido na reprodução. Nesse momento, o implicado do registro soma-se ao implicado ambiente. O que poderia nos levar a pensar toda gravação como, em última instância, uma construção "ao vivo", uma relação com o espaço.

Sistemas como o THX ${ }^{1}$, desenvolvido por Holman e institucionalizado em 1983 como uma divisão da Lucasfilm (constituindo em 2002 uma empresa independente), preveem justamente uma relação definida com esse espaço. O THX não é um sistema de gravação, mas uma "arquitetura" de exibição. Sua premissa é que todo som mixado e reproduzido segundo parâmetros certificados pela empresa soará exatamente da forma

1 Padrão de sonorização de salas de cinema que inclui não apenas equipamentos como alto-falantes e amplificadores devidamente certificados, mas também um projeto arquitetônico que possibilita a reprodução de todo o espectro de frequências audíveis. Criado por Tomlinson Holman e nomeado a partir de suas iniciais. 
como foi concebido na mixagem. Chion (1994) afirma que o THX foi pensado como uma consolidação do ideal de potência "seca" do cinema contemporâneo. Ou seja, enxuga-se o excesso de reverberações, o excesso de frequências estacionárias e/ou não desejadas. Ao definir estrutura, tamanho, formato e materiais usados na sala, o THX pretende controlar o processo de contração e de dispersão dos sons. A ecologia do espaço sonoro está nas mãos de um projeto que é objetivo e totalizante. Não há possibilidade de sons não desejáveis. Da mesma forma como os estúdios (tanto cinematográficos quanto fonográficos) tentam eliminar a assinatura sonora das salas de gravação, os sistemas de reprodução também ignoram a diversidade de escutas possíveis na sala de exibição em função de uma única escuta ideal. É como se ignorassem a escuta coletiva, uma vez que cada espectador está em um ponto diferente da sala, e procurassem definir centenas de lugares centrais. Um ponto de escuta privilegiado que pode, de forma análoga, lembrar a construção da perspectiva renascentista que tinha como centro o olhar do pintor. A escuta contemporânea nas salas de cinema tem como projeto ideal a ubiquidade da cadeira do mixador.

As assinaturas sonoras do espaço são banidas da mesma forma que as assinaturas sonoras das tecnologias. Equipamentos de primeira linha primam pela não coloração dos sons (não privilegiando quaisquer faixas de frequência), pela ausência de distorção harmônica total, pela potência etc. Sistemas de alta-fidelidade não corrompem o som original.

Mas que som original é esse?

O mito do "som original" pode ser também identificado no surgimento de algumas práticas destoantes da hegemonia digital atual, mas que não deixam de, ao mesmo tempo, corroborar modelos mais correntes de produção. Como que na contramão da popularização de sistemas digitais nas salas de cinema e nos estúdios de gravação, vemos a valorização de determinadas práticas associadas à "impureza" do analógico, como se este fosse dotado de um nível de "realidade" inexistente no digital. Essa apropriação do ruído analógico - seja por ferramentas digitais, seja pelo resgate de equipamentos antigos revestiu-se de valores estéticos imediatamente associados a determinados grupos ou estilos musicais e a determinados realizadores experimentais. A "impureza" analógica traz as marcas de um sentimento "retrô" que se fundamenta menos na eficiência ou na objetividade do que na recuperação de afetos construídos ao longo do tempo. São memórias sociais embutidas em mecanismos que retornam, reavivadas por novas gerações e remodeladas 
por novos dados de ambientes intensamente tecnológicos². Como diz Simon Reynolds: "a cultura pop contemporânea é viciada em seu próprio passado" (REYNOLDS, 2011, p. 403).

Citemos um exemplo do campo musical... Nos anos 1990, época em que o som digital se consolidava como aposta das indústrias eletrônicas e de música, encontramos a seguinte consideração sobre o fenômeno "lo-fi" analógico que tomou conta das gravações de rock:

O vice-presidente sênior de artistas da Columbia Records observa: "Chiado de fita, ruído de amplificação de guitarra, resíduos de menor importância. Cinco anos atrás, nós teríamos limpado tudo isso. Mas hoje a sabedoria que prevalece é ser lo-fi [grifo do autor] e deixar o ruído virar parte da música." Isso na tentativa de "capturar um som menos digital" e segue de braços dados com a adoção dos "ruídos incidentais e incorporá-los na mixagem para alcançar um sentimento de realidade ampliado" (CHUN apud EVENS, 2005, p. 177).

As práticas de gravação, mixagem e masterização cada vez mais dependiam de processos digitais. Mesmo assim, a utilização de elementos “lo-fi”, com ruídos "analógicos", dava uma sensação de "realidade" à música desses grupos. Concedia autenticidade ao som. Apesar de se propor a oferecer uma experiência "pura", não contaminada por ruídos, o som digital - pelo menos em uma fase inicial — foi recebido com suspeita e mesmo com desagrado por aqueles que o viam como menos caloroso, menos humano. O mesmo pode ser dito das imagens digitais.

Esse tipo de nostalgia foi bem menos evidente na atividade cinematográfica. O apelo estético do analógico, visto como mais expressivo por parte da produção fonográfica, não despertou grande interesse de uma indústria cuja maior preocupação era a previsibilidade dos eventos na sala de cinema. A diferença de uma experiência coletiva para uma que não dependia de uma audição conjunta certamente também teve influência na definição de um modelo digital de escuta cinematográfica. Lembrando que, mesmo quando o padrão de reprodução sonora no cinema ainda era analógico (o Dolby Stereo, por exemplo), sua grande

\footnotetext{
2 Aqui é bom destacar a definição de Jacques Le Goff para memória coletiva: um campo de disputas entre as diferentes forças sociais. O que a história deixa de lembrar ou o que ela traz à tona são indícios desse tipo de manipulação.
} 
virtude era justamente a segurança em relação aos diferentes modelos de som existentes no mercado. O Dolby não era ousado, era apenas compatível.

Ruídos analógicos foram eliminados de forma mais radical com o digital do que o foram com os filtros do Dolby Stereo. O implícito, no digital, não é algo que "vaza" apesar das barreiras tecnológicas. Desta vez, ele não faz mais parte do repertório das tecnologias. De forma similar ao mascaramento do ruído pelo uso de efeitos psicoacústicos, os novos dispositivos "ignoram” o que não é sinal. A diferença fundamental é que o condicionamento se dá sobre a "percepção" da máquina. Variações de sinais elétricos, medidas como unidades discretas, prescrevem rigidamente o que entra e o que não entra. O digital funciona como uma experiência de apenas "figuras", sem "fundos". Já o silêncio do Dolby Digital nos anos 1990, por exemplo, deveria ser absoluto, uma vez que silenciavam as máquinas, silenciava-se a sala e silenciava-se o espaço original. O espectador parecia, dessa forma, mais encarcerado do que na metáfora comumente usada dos prisioneiros da caverna de Platão.

Ainda sobre os sistemas auto-organizados, segundo a proposição de Atlan, a capacidade de lidar com novos arranjos, bem como com elementos variáveis e aleatórios, levaria esses sistemas complexos a identificarem padrões que são incorporados pelo sistema. Esses padrões constituem uma espécie de memória material utilizada como fundo para o aumento da diversidade e da complexidade. Tecnologias podem ser vistas como exteriorizações dessas memórias. Memórias que o próprio Atlan identifica também como formas de linguagem:

A utilização de uma linguagem falada, depois escrita, é de fato uma extensão fundamental das possibilidades de armazenamento da nossa memória que, graças a isso, pode sair dos limites físicos do nosso corpo para estar interposta quer nos outros quer nas bibliotecas. Isto significa que, antes de ser falada ou escrita, existe uma certa linguagem sob a forma de armazenamento de informações na nossa memória (ATLAN apud LEGOFF, 1990, p. 425)³.

Sair dos limites físicos do corpo significa processar e sedimentar essa relação entre memória e linguagem, esta última não apenas no nível verbal. Essa linguagem, presente nas

\footnotetext{
3 Para Le Goff, a expansão e concessão da memória às máquinas trouxeram mudanças não apenas para o processamento e arquivamento de informações, mas também para a própria ideia de humano. Novas formas de percepção e relacionamento com o mundo surgem a partir dessa exteriorização da memória.
} 
diferentes formas de tecnologias, é incorporada e naturalizada, como se fosse parte indissociável do humano. Friedrich Kittler (1990) chama as diferentes mídias de Aufshreibesysteme: sistemas de notação. Seriam como repertórios culturais que se inscrevem profundamente nos corpos das pessoas, criando marcas, cicatrizes, customizando, cerceando algumas ações e estimulando outras. É importante notar o quanto esse processo é intensamente físico, tanto de uma parte como de outra. Há uma necessidade urgente do atrito entre corpo e máquina para que ambos se reconheçam e passem a funcionar em conjunto.

Dessa forma, organizados como uma espécie de linguagem — que é portadora de sentidos que só podem ser apreendidos através do domínio de códigos específicos os dispositivos técnicos podem ser pensados também como formas de memória. Rotinas estabelecidas, hábitos cristalizados, sobre os quais lançamos novas experiências, produzindo resultados sempre distintos. Evitamos assim a estabilização através de um embate eterno entre códigos já estabelecidos e novos estímulos do ambiente. Instigamos a capacidade criativa dos sistemas ao minimizar a possibilidade de equilíbrio.

A relação entre tecnologias e passado indica, também, um modo de ouvir não apenas através das tecnologias, mas de ouvi-las elas próprias. A contextualização histórica nos permite descrever uma inaudibilidade das atuais tecnologias de som e uma incômoda audibilidade de tecnologias “antigas". O regime de inaudibilidade preza pela transparência, isto é, não percebermos a mediação tecnológica presente e, consequentemente, atribuirmos um grau de "fidelidade" maior ao som. Muito embora a maior preocupação das tecnologias digitais seja em relação à definição, a ideia de fidelidade ainda paira como um importante - e cíclico — elemento do imaginário tecnológico.

A possibilidade de "ouvir" o passado através de seus ruídos implica uma desnaturalização da própria ideia de ruído e uma relativização de qualquer relação entre o que é reproduzido e o que é efetivamente ouvido. Os efeitos de tornar o passado audível não incorporam apenas processos psicoacústicos, mas também construções simbólicas acerca das tecnologias de som.

\section{Base material de sons e imagens}

Sons tratados como características ou indícios de objetos visíveis na tela são a forma mais comumente utilizada no cinema clássico narrativo. Até os anos 1970, salvo algumas experimentações anteriores, não era esperado dos elementos sonoros de um filme nada além de 
reforçar o que a câmera enquadrava ou sugerir o que poderia ser enquadrado. Sons referiam-se a coisas e, por isso mesmo, tinham sua razão de ser dentro da narrativa. É sintomático que o uso do som de forma não representacional tivesse um maior impacto em formas artísticas que não o cinema. Mesmo as práticas de atribuir ao universo sonoro características dissociadas de objetos concretos, relacionando-os com afetos originários do contexto industrial e do pósguerra, como nos movimentos de vanguarda do século XX, encontravam dificuldades para sua preservação. A possibilidade de "ouvir" a produção artística do início do século passado foi prejudicada pelo próprio uso limitado das tecnologias de gravação:

Como o próprio modernismo, o fonógrafo simbolizou um novo dia para a auralidade através de sua habilidade de reapresentar praticamente qualquer som de novo e de novo ao sensorium e ao registro histórico. Entretanto, da forma como aconteceu, a fonografia estava ocupada gravando outras coisas além da produção sonora da arte moderna e, consequentemente, o registro de gravações é tênue (KAHN, 1999, p. 5).

Tecnologias forneciam a inspiração para novas formas de ouvir, porém não possibilitaram a recuperação dessa escuta. Gravações, pelo modelo constituído em torno do fonógrafo, ainda eram gravações de alguma coisa. O caráter representacional do registro sonoro inibia a relação direta com as dimensões materiais da gravação.

Muito embora nos anos 1950 e 1970 determinados gêneros cinematográficos explorassem novas negociações entre sons e imagens, ou entre sons e espaço, novamente a construção narrativa dificultava um modelo outro que não fosse o de uma descrição do que se via. $\mathrm{O}$ estranhamento era condição inescapável quando tratando de outros mundos ou outras realidades (no caso da ficção científica, por exemplo), mas, no fim, os outros mundos acabavam sendo uma analogia do mundo de sempre. A lógica mantinha-se a mesma.

Ouvir através das tecnologias ainda era parte do acordo entre espectador e filme. Ao cunhar a expressão "contrato audiovisual", Chion (1994) tenta descrever os diferentes usos de som e imagem que tanto a teoria quanto a prática têm normalmente deixado em segundo plano, uma vez que a relação hierarquizada entre os dois ainda é tida pela acepção comum como natural e inevitável. Para a argumentação de Chion, o dado tecnológico funciona como moderador desse contrato justamente por permanecer "ausente". O "silêncio" dos alto-falantes, 
que Chion identifica em sistemas como o Dolby; ou a potência "seca", em arquiteturas como o THX, são exemplos de desaparecimento da tecnologia em função da experiência imersiva. O que talvez não esteja sendo considerado nessa argumentação é que essa experiência, a partir da ocultação do dispositivo sonoro, continua reforçando modelos de representação pelo som. Para Birtwistle (2010), o problema nesse tipo de concepção é o de manter o som como algo secundário, como atributo, característica ou efeito de alguma outra coisa.

Ao reforçar a ideia de filme como um texto significante, com ênfase na atribuição arbitrária de sentidos a coisas através de sons e imagens, perdemos a noção da condição material que todo produto audiovisual tem em sua base. Todo filme funciona a partir de premissas anteriores à construção linguística. O sentido do filme está primeiramente atrelado a questões não textuais.

A questão da materialidade dos filmes é central para o conjunto de práticas e teorias sobre o "filme estrutural", em alta entre os anos 1960 e 19704. A relação entre as proposições acerca do filme estrutural e as práticas de vanguarda é evidente no que diz respeito à imagem. Propriedades visuais como cor, grão, movimento etc. são elencadas entre as principais inquietações dos cineastas. O filme deveria debruçar-se sobre sua própria matéria e realizar uma autorreflexão. Os aspectos visuais eram tratados como as propriedades características mais importantes do filme. Porém, a relação direta entre o suporte fotoquímico da película e sua manifestação objetivamente visual deixava o som fora da conversa.

Cada filme é um registro (não uma representação, não uma reprodução) de sua própria feitura. A produção de relações (take para take, take para imagem, grão para imagem, dissolução da imagem para grão etc.) é uma função básica que está em oposição direta à reprodução de relações (GIDAL, 1978, p. 2).

Mesmo quando mencionado por realizadores críticos à forma tradicional de filmar, o som permanece fora do projeto estrutural: como se recusá-lo fosse uma forma de não

\footnotetext{
4 O "filme estrutural" é um movimento cinematográfico de vanguarda surgido nos anos 1960 nos Estados Unidos, migrando, posteriormente, para o Reino Unido. Dele fizeram parte realizadores como Peter Gidal, Michael Snow, Tony Conrad, Peter Kubelka etc. De um modo geral, os artistas se preocupavam mais com a "forma" do filme do que com seu "conteúdo". Não confundir com o termo "estruturalismo"; apesar de parecidos, não são a mesma coisa. Para maiores informações, consultar o livro Structural film anthology, de Peter Gidal, constante na bibliografia.
} 
ceder às imposições clássico-narrativas. Stan Brakhage deixa claro seu incômodo em relação ao uso de som em seus filmes:

Quanto mais acostumado eu ficava com a estética do som, menos eu sentia a necessidade de um acompanhamento sonoro para as imagens que eu fazia... Quanto mais dirigidas ao silêncio tornavam-se minhas filosofias criativas, mais inspirada pela música tornou-se minha estética fotográfica e meu efetivo método de edição, ambos produzindo um vir-a-ser da relação fisiológica entre ver e ouvir na construção de uma obra de arte em filme (apud JORDAN, 2003, sem paginação).

O som não é, portanto, uma questão para a vanguarda cinematográfica. Antes, sua ausência seria a forma mais clara de oposição ao modo institucionalizado de fazer filmes. Isso é aparentemente contraditório, uma vez que uma das maiores preocupações do filme estrutural seria com a duração: "No filme, a duração como parte material do tempo é a unidade básica" (GIDAL, 1978, p. 8). A duração era fundamental para "decifrar" a base material do filme e sua articulação com novas formas mediadas de "ver". As técnicas deveriam ser "lidas" como criadoras de formas. Essas formas, em última instância, deveriam se tornar o "tema" do filme, sua "narrativa". O filme estrutural propõe uma fetichização da forma.

A desconstrução da narrativa, embora inevitável em alguma medida, não é vital para esse tipo de argumentação. Ela é, contudo, útil por alienar os códigos institucionalizados. O sentido do filme não é mais exclusividade dos mecanismos internos de narração. Indo além, não é mais determinado por condições de produção. O evento cinematográfico alcança autonomia a partir de sua natureza temporal e espacial.

O som, como dissemos, apesar de sua óbvia existência no tempo e no espaço, não é levado em conta na proposta de Gidal.

Partindo igualmente das proposições de Chion, Birtwistle (2010) descreve a noção de "audiovisualidade", em uma tentativa de incorporar o som a esse contexto de análise material do filme. Para Birtwistle, a relação entre som e imagem faz parte inseparável da experiência do filme. Altman $(1992 ; 1995 ; 2004)$ deixa bem claro que, mesmo nas formas mais tradicionais, nunca houve uma experiência cinematográfica sem som. E esse som não era apenas aquele reproduzido mecanicamente, e nem mesmo apenas aquele executado por músicos ou sonoplastas, mas o som do próprio ambiente. A plateia e uma série de outras 
condições indiretas ajudavam a construir esse espaço sonoro. Para Birtwistle, essa forma mais abrangente de pensar a dimensão sonora do filme, deslocando-a de um uma banda sonora fechada e não permeável para um conjunto que ultrapassa o próprio dispositivo, traz a discussão da experiência para um nível extratextual, não consciente.

Apesar do fato de que um cineasta como Stan Brakhage possa fazer a escolha consciente de não gravar uma pista sonora para um filme, exibições de seu trabalho não são nunca uma experiência puramente visual (BIRTWISTLE, 2010, p. 18).

Uma segunda característica dessa noção de audiovisualidade é a de que o cinema e as demais formas audiovisuais são mídias transensoriais. Isto é, o filme não pode ser reduzido às dimensões visuais e sonoras apenas. Essa seria uma forma de ignorar muitas das diferentes afetações físicas que ele pode suscitar. O termo "audiovisual” é, por si só, excludente, não dando conta das diversas qualidades sensíveis da experiência cinematográfica caso consideremos os demais aspectos materiais do filme.

Ainda, como terceira característica da audiovisualidade, devemos entender as relações entre som e imagem como sempre cambiantes. Ao mesmo tempo em que interpretamos intelectualmente os sentidos do filme em um nível textual, as diferentes materialidades do meio despertam e trabalham em um nível afetivo. O filme é composto de diferentes camadas de significação operando simultaneamente e das quais não temos necessariamente consciência.

Algumas dessas camadas, por estarem fora de regimes estabelecidos de percepção, tornam-se irreconhecíveis. Contestam modos hegemônicos de perceber o filme, não se inserindo em um campo epistemológico "legítimo". Funcionam à margem dos modos clássicos de ver e ouvir, e nisso reside sua força. Como "ruído", o som vale-se de suas propriedades materiais para questionar o caráter representacional com o qual é usualmente associado. Ele interfere, distrai e desorganiza.

\section{Ruído de fundo e ruído de máquina}

O ruído de fundo e o ruído de máquina estão associados à interferência das tecnologias na experiência do filme. Eles desviam a atenção da estrutura narrativa, atrapalhando a "leitura" 
do filme. Por esse motivo, o "avanço" tecnológico teve sempre como base discursiva a eliminação do ruído, favorecendo a transparência das tecnologias de gravação. O ruído sempre foi tido como um problema a ser eliminado, sendo que a perfeição técnica não é de forma alguma um privilégio das tecnologias digitais. A promessa de um mundo não perturbado por tais elementos indesejáveis e com ênfase total na parte "boa" do som — o sinal — está presente na fala de Donald MacKenzie nos anos 1930: "O objetivo de toda gravação é fornecer um som que será indistinguível do som que alguém teria da fonte original caso estivesse lá" (MACKENZIE, 1931, p. 84). Está também no trabalho contemporâneo de Stanley Alten: "De fato, pelo motivo da redução de ruído no processamento digital ser tão eficaz, livrar-se do ruído gravado e de sistema tornou-se um problema bem menor do que já foi um dia” (ALTEN, 2011, p. 176).

Alten sugere, nesse trecho, que o ruído é especialmente relacionado ao som analógico. Ao considerarem o analógico como fonte de ruídos - e o digital, consequentemente, como isento dele - , autores voltados para a descrição de práticas e métodos de produção e pósprodução, como é o caso de Alten, retiram o ruído da pauta do cinema contemporâneo. Não sendo mais um problema "real" a ser contornado, o ruído é tratado como perspectiva nostálgica, como algo que houve, mas que, atualmente, apenas pela simulação controlada poderia ser "reproduzido". Isto é, o ruído perdeu sua potência disruptiva, sendo encapsulado em pastiches digitais. Ele é apropriado como uma memória afetiva de tecnologias passadas, mas que não pode ser completamente ressuscitada por dois motivos: primeiro, as tecnologias "evoluíram" e seria um contrassenso retornar a um estágio mais primitivo das formas de fazer filmes; segundo, o ruído estetizado não contesta nenhum tipo de ordem, função plástica ou de comunicação. Ele, antes, é fruto de uma lógica própria que o usa como o "outro" da tecnologia. Um fantasma que nos lembra do quanto avançamos para um futuro limpo e claro. O ruído funciona como um mito.

Ao mesmo tempo, o tema é sintomaticamente negligenciado pelos textos do campo de estudos cinematográficos. Ao passo que os estudos de comunicação apresentam uma postura relativamente conservadora, ao adotar o modelo matemático de Shannon e Weaver (1964), em que o ruído é uma interferência negativa no sistema, os trabalhos sobre filmes, de uma forma geral, não sabem como lidar com o tópico. Ele transcende questões hermenêuticas, dificultando o exercício de análise fílmica, tão caro aos estudos de cinema. O motivo é justamente porque ruídos não devem ser notados: da mesma forma que as tecnologias de som em geral. Ter a consciência do ruído é ter a consciência do dispositivo mediando a 
experiência. E aqui voltamos — mais uma vez — à questão da referência que sons devem fazer ao mundo real: a fidelidade de representação.

A aparência simulada de erro tornou-se um pastiche bastante comum em produções cinematográficas a partir dos anos 1990. Como um fenômeno relativamente recente, alguns segmentos da indústria passaram a apostar em uma "imperfeição técnica" para dar ao filme um maior índice de credibilidade.

O filme A bruxa de Blair (The Blair witch project, Eduardo Sánchez; Daniel Myrick, 1999) conta a história de três estudantes que desaparecem perto de Burkittsville, Maryland, em 1994. Somos informados de que os estudantes nunca foram encontrados e de que os "fatos" concretos sobre o seu desaparecimento são deduzidos a partir de imagens "amadoras" encontradas por acaso. O impacto que o filme teve mundialmente se deve, em parte, ao seu estilo "documentário", induzindo as plateias a acreditar que se tratava de uma história real. Parte desse efeito foi conseguida por uma estratégia que articulava narrativas transmidiáticas, como relatos em websites contendo reportagens ou registros policiais. O filme teve um retorno aproximado de US\$ 248 milhões, um grande resultado para um projeto despretensioso.

A ausência de condições técnicas ideais como iluminação, boa definição de imagem e de som, assim como os "erros" de filmagem — enquadramento instável, movimentos aparentemente caóticos da câmera, impossibilidade de ouvir perfeitamente o que é dito ou o que acontece fora de quadro - , dá ao filme uma aparência de "real". A produção finge ignorar a mediação técnica, fazendo com que o filme pareça um registro "verdadeiro" (muito embora não transparente) de algo que aconteceu de fato. É como se as imperfeições nos dissessem que não houve grande investimento para convencer o público daquela realidade. O ruído em imagens e sons nos leva a pensar que o material não sofreu nenhum tipo de intervenção "artificial" após o registro inicial, o que seria bastante incomum, dada a quantidade de recursos a que temos acesso hoje na gravação e edição de filmes. Consumimos o produto como se fosse o "material bruto" da filmagem, resultado de um registro fortuito, acidental. Enquanto imagens e sons tecnicamente perfeitos são um sinal de manipulação, em materiais mal acabados nós encontramos uma possibilidade do concreto: a assinatura "inocente" da máquina sem a intervenção criativa do diretor. A máquina seria imparcial na medida em que não adiciona "intenções" ao filme, mas é também opaca por esconder sob o manto do ruído os detalhes de sons e imagens. 
Deste modo, os olhos e ouvidos do dispositivo assumem uma postura de apresentar a realidade, mas, ao mesmo tempo, de apresentar a si mesmos. Tornam-se visíveis e audíveis. Não é o caso de negar a metáfora da janela através da qual temos acesso direto ao mundo, como proposto por Bazin: agora percebemos que essa janela obrigatoriamente distorce esse mundo, e essa distorção é estetizada.

O século XX, especialmente a partir dos anos 1980, demonstrou um interesse crescente na reformulação e domesticação do ruído enquanto matéria afetiva — desde a incorporação de elementos estéticos de décadas passadas à música, arquitetura, design etc. até a exploração de diferentes tipos de suportes para gravação e exibição de filmes. Assim como no caso do renascimento do vinil para um nicho específico do consumo de música, a utilização de negativos de diferentes bitolas ou de câmeras antigas ou artesanais para alcançar efeitos propositalmente "sujos" ou "imperfeitos" tem como objetivo tornar a tecnologia aparente. O ruído é algo que se espera, como manifestação da base material tanto do áudio quanto do vídeo. Em uma via oposta ao que o desenvolvimento técnico de suportes - analógicos e digitais - e de processos de finalização tem sugerido ao longo dos anos, experimentações de alguns realizadores independentes tomam a matéria como elemento de significação e minimizam a importância da representação de som e imagens como indícios de uma realidade previamente dada.

Mesmo nas formas mais idealizadas de tecnologias sonoras é possível identificar-se a assinatura de um tipo de prática cinematográfica. Essa prática está associada a fatores estéticos e econômicos, mas igualmente a fatores ideológicos. O autoapagamento das próprias tecnologias é um desses fatores. A execução técnica da noção de fidelidade não consegue esconder essa sonoridade específica de cada modelo tecnológico. Tecnologias deixarão sempre rastros de diferentes tipos de ruídos, inevitavelmente. O dispositivo enquanto ideal é uma coisa, mas a concretização desse dispositivo em sistemas efetivos estará sempre sujeita a um nível maior ou menor de desorganização e entropia.

A invisibilidade das tecnologias é um efeito mais eficientemente levado a cabo pela proximidade. O passado é sempre mais audível do que o presente, seja pelo interesse das novas tecnologias continuarem a se impor como transparentes diante das "antigas", seja pela dificuldade do espectador identificar diferentes tratos sonoros como comparação a tudo que "é ouvido" fora da sala de cinema. Quanto mais comuns os modos de escuta, mais naturalizados. Identificar os chiados de fitas magnéticas ou os cliques intermitentes 
do som óptico é bem mais simples do que se referir ao "silêncio" pós-Dolby. Nesse caso, para Chion, a dimensão silenciosa é tão intensa que a relação inverte-se: os alto-falantes é que passam a ouvir a plateia. Ela não consegue ouvir os sons da máquina: mas até quando?

O ruído torna-se, portanto, instável, obedecendo a condições contemporâneas de deslocamento. O dispositivo só pode ser notado quando percebido como distante. Nesse sentido, cliques, chiados etc. provocam um sentido de passado que a reprodução sem "partes móveis" ainda não consegue. E nem é esse o seu projeto. Como dissemos, a transparência das tecnologias digitais (de fato, de qualquer nova tecnologia) só é afirmada pela opacidade das antigas. Isto é, uma apenas se afirma enquanto "oposta" à outra. Critérios técnicos, embora protegidos por argumentos racionais, demonstram, corriqueiramente, um forte apelo afetivo.

No caso de filmes antigos, o ruído de fundo bem como a compressão da voz ou a limitada extensão do espectro de frequências são logo abstraídos para que o espectador se concentre no conteúdo das falas. A escuta adapta-se a condições "imperfeitas" mediante uma negociação entre a percepção das diversas características físicas do som e a interpretação desse mesmo som através de estruturas linguísticas e/ou de representação. Não estamos falando de modos fixos de "leitura" (e o próprio termo já indica uma maneira tendenciosa de analisar a questão), mas de modos que são determinados no momento da exibição do filme e em relação a um contexto histórico e social. A "estética do imperfeito" atende a demandas da indústria contemporânea sendo que a própria criação de afetos a partir do ruído é uma de suas estratégias.

Ainda assim, o contrato estabelecido entre filme e plateia não é tão draconiano e exibe brechas em que as duas partes podem desenvolver alternativas aos modos préprogramados de ouvir um filme.

Podemos pensar, especificamente, nos efeitos dos ruídos de pistas analógicas de som em filmes antigos sobre a experiência do espectador. Em particular aqueles produzidos pelo som óptico. Aqui, descrevemos o ruído de fundo (ground noise) como aquele produzido por aspectos físicos da película e que se apresenta quando de sua exibição. Os arranhões e demais formas de desgaste na pista óptica, produzindo um contínuo som de "fritura", são um bom exemplo. Já os ruídos de sistema não necessitam que o filme seja projetado para existirem. A corrente elétrica se encarrega de produzi-los assim que o circuito é ligado. Possuem uma independência do som gravado na pista sonora e criam um fundo constante. 
Tanto ruídos de fundo quanto ruídos de sistema podem ser pensados como o "som do filme", literalmente falando:

Juntos, o grão e o arranhado da pista óptica encerram um aspecto do que pode ser pensado como o som do filme ele mesmo: o som produzido por uma pista sonora não modulada, um soar do material fílmico e suas bases tecnológicas (BIRTWISTLE, 2010, p. 86).

Outros ruídos, produzidos por processos mais indiretos, também são somados aos dois mencionados anteriormente. Há o ruído de fundo do material gravado para o filme, anteriormente à mixagem, o que, de um modo geral, era feito em meio magnético até os anos 1990. O chiado da fita, por mais invasivos que pudessem ser os filtros aplicados nos processos de gravação, edição e mixagem, sobrevive indelével. Fruto do atrito entre cabeçotes e fita, o chiado mistura-se ao sinal e não pode ser removido sem o custo de outras frequências serem também atingidas. Sistemas de redução de ruído como o Dolby $A$, por exemplo, trabalhavam tendo em vista o efeito de hiss presente nas diversas faixas de frequência e mascarando a ação dessas frequências através de modificações na gama dinâmica dos sons gravados.

Alguns artifícios utilizados para a diminuição de ruídos de fundo acabam por gerar uma sonoridade própria de cada época. Assim como, a partir dos anos 1970, o Dolby tornou-se praticamente um sinônimo de redução de ruídos, filmes da década de 1920 e 1930 utilizavam um tipo de gate bastante acentuado para "emoldurar" a fala dos personagens. Gates são dispositivos que reduzem o volume do som a partir de um nível preestabelecido. Nesses filmes, toda vez que algum silêncio surgia, o gate cortava o volume do som, criando uma passagem irreal entre fala e não fala, sem a existência de um fundo que disfarçasse os cortes. Os dois níveis de ruídos — o ruído de fundo dos processos de gravação e edição e o ruído de fundo da própria película rodando - não se confundiam e era claro quando a montagem silenciava o primeiro, deixando o segundo aparente.

Ainda nas primeiras décadas do cinema, a pouca sensibilidade de sistemas de gravação em negativo de filme - como o Photophone - também produzia um tipo bem específico de sonoridade. No sistema, um pequeno espelho refletindo um feixe de luz movia-se de acordo com a intensidade variável de uma corrente elétrica (produzida pelo microfone). 
Ao mover-se, fazia com que a luz produzisse oscilação análoga à da corrente elétrica. Por não responder tão bem às pequenas variações, o sistema normalmente descartava sons de baixa intensidade e, ao mesmo tempo, registrava os sons mais altos sem muita sutileza. O som era, de modo geral, bastante alto e saturado.

Os efeitos descritos se impunham sobre um estilo de montagem que se pretendia invisível, ou seja, não poderia demonstrar a existência de uma intervenção nem sobre a imagem nem sobre o som. Este último sofria uma cobrança ainda maior, pois, sendo inevitável a existência do corte e das passagens entre planos, ao som cabia a tarefa de criar a continuidade, escondendo o ponto de vista das máquinas. Demonstrações claras para nós hoje das tecnologias "ultrapassadas" de cada um desses sistemas, tais recursos passavam por naturais e dificilmente eram encarados como sonoridades "inadequadas" em suas respectivas épocas.

Ainda hoje, os sons indesejáveis que porventura entram nas gravações, apesar do caráter direcional de microfones para cinema e do desenvolvimento de estratégias cada vez mais sofisticadas para exclusão de elementos externos às cenas, também podem representar um tipo de perturbação durante a audiência de um filme. Não são poucos os casos de sons que não deveriam "estar ali”, mas que, por um descuido técnico qualquer, são "descobertos" após o filme pronto.

A invisibilidade do dispositivo, por sinal, dá-se de forma também literal pela necessidade de esconder microfones e demais acessórios técnicos no set de filmagem. Um dos grandes pecados do profissional de som no set de filmagem é, como todos sabem, deixar o microfone ser flagrado pela câmera.

Birtwistle (2010) entende o sentido de passado produzido pelos ruídos de fundo e pelos ruídos de sistema como atrelado à perda de referência temporal que sons contínuos exercem em nossa consciência. Os microssons que constituem a pista óptica produzem um efeito ininterrupto e sem referência tonal, próximo ao de um drone.

Não há frases, não há grupamentos, nenhuma padronização ou variações memoráveis dentro da duração ocupada pelo som. No som do ruído de fundo e dos estalos da pista óptica, o mesotemporal, o macrotemporal, o objeto sonoro e os domínios microssonoros, consequentemente, se mesclam para se tornarem uma experiência sônica, colocando em movimento a estrutura 
temporal de referência que trazemos para sustentar nosso engajamento com o texto do filme. [...] Esse som da tecnologia é não direcional e não narrativo, no sentido em que nem apoia a narrativa, nem demonstra algum desenvolvimento interno. Tais sons podem, portanto, ser pensados em termos de estase e suspensão (BIRTWISTLE, 2010, p. 104).

A experiência física da escuta sobrepõe-se ao desenvolvimento linear presente na narração cinematográfica e mesmo em estruturas musicais. Birtwistle associa o efeito do drone à eliminação da horizontalidade da experiência sonora, situando o espectador em um "presente" eterno. Esse presente expande-se em várias direções, escapando às referências temporais com que usualmente nos orientamos. A impossibilidade de acompanhar cada microelemento da textura de sons (como acontece também em sons de elementos naturais como vento, fogo etc.) apresenta à nossa consciência uma multiplicidade contínua, uma duração no sentido bergsoniano, que nos levaria a entrar em um mundo interior de pensamentos e memórias. A relação entre drone e memória contribuiria para a sensação de passado evocada por determinadas sonoridades. A associação entre ruídos de fundo e passado, antes mesmo dos primeiros serem pensados enquanto assinaturas de tecnologias antigas, dá-se pela não resolução de uma escuta constantemente situada entre o consciente e o inconsciente. A identidade dos sons permanece obscura uma vez que não se relaciona a elementos textuais, colocando em xeque qualquer referência a questões narrativas.

Nesse sentido, é mais difícil atribuir tais características ao ruído digital. Talvez seja difícil inclusive pensá-lo segundo os mesmos parâmetros.

\section{Conclusão}

O discurso, encampado por tecnologias atuais ou antigas, que defende uma busca incessante pelo aprimoramento do registro sonoro revela algumas facetas interessantes não apenas das tecnologias, mas do corpo social como um todo. Investigar as relações construídas historicamente entre esse corpo e os dispositivos tecnológicos é tentar lançar um olhar cuidadoso e menos assertivo sobre nossas representações de mundo. 
Este trabalho parte da perspectiva de que as tecnologias não são um fator ingênuo dentro das relações discursivas, semiológicas ou epistemológicas presentes na sociedade. A análise do som (especialmente o som do filme) a partir de premissas textuais e de perspectivas interpretativas retira deste (ou limita significativamente) a capacidade de atuar em dimensões físicas, a partir de suas condições materiais. Ao som é negada uma ação direta sobre as coisas e sobre o próprio homem, ação que prescindiria da necessidade de interpretação ou de atribuição de significados. O som enquanto produção de "presença".

Gumbrecht (2004) propõe uma tipologia que descreve, de forma gradual e não estanque, especificidades das chamadas "culturas de presença" e das "culturas de sentido". Entre as características a serem percebidas nas culturas de sentido, estaria o pensamento enquanto autorreferência humana (consciência ou res cogitans); ao passo que, nas culturas de presença, o corpo coloca-se como referência central. Ainda, em uma cultura de sentido, haveria uma separação entre homem/consciência/sujeito e mundo/matéria/objetos; numa cultura de presença essa separação é menos visível, o homem não se coloca como excêntrico ao mundo e os objetos portam sentidos que não necessitam de uma interpretação para vir à tona. Em uma cultura de sentido, essa exegese é fundamental para a validação de qualquer conhecimento; em uma cultura de presença, por outro lado, esse conhecimento é revelado por deuses, pelas próprias coisas, por epifanias. Nesta, o conhecimento seria compartilhado pelos objetos existentes que só podem ser entendidos via uma disponibilidade de cada um e por um laço fugaz que une tudo. Não cabe ao sujeito promover esse conhecimento do mundo, mas a este próprio desvelar-se.

O “espaço" se apresenta como dimensão primordial em culturas de presença. É pelo espaço que os corpos se relacionam entre si e com o cosmos. Como consequência dessa relação entre corpos e espaços, é inevitável que o atrito se faça presente. Esse atrito pode resultar, facilmente, em práticas violentas. $\mathrm{O}$ corpo é exigido de diferentes maneiras: seja em rituais ou na forma de se apresentar diante de outros corpos.

O atrito é, não à toa, uma das principais causas do ruído em tecnologias de som. Violentamente, ele manifesta-se sobre o sinal, deturpando a experiência "ideal" de audição de músicas e filmes. Tecnologias de redução de ruído pautaram-se, desde sempre, por uma tentativa de prever o comportamento desse elemento absolutamente imprevisível. Partem da assunção de que há partes a serem preservadas e outras a serem descartadas na escuta. Modos de perceber são organizados nessa relação tecnicamente mediada. 
Tecnologias refletem e são reflexo de contextos reticulares. Como tal, não podem ser vistas como elemento inócuo. O humano constrói e é construído pelo técnico. A técnica não está presente apenas nos dispositivos, mas estes são uma formalização de discursos sociais: desde o somatismo tecnológico de Ernst Kapp (2007) até as teorias mais gnósticas como a da redenção do humano pela máquina, como nos descreve o sociólogo Hermínio Martins com seus conceitos de imagem fáustica e de imagem prometeica da técnica (MARTINS, 2012; 2005; 1996). Tendo isso em vista, talvez possamos tanto quanto entender as tecnologias através da noção de humano, compreender o humano como igualmente refletido em suas tecnologias.

\section{Referências}

ALTEN, Stanley. Audio in media. Boston: Wadsworth, 2011.

ALTMAN, Rick (Ed.). Sound theory/sound practice. New York: Routledge, 1992.

. Nascimento da recepção clássica: a campanha para padronizar o som. Imagens, n. 5, p. 41-47, ago./dez. 1995.

. Silent film sound. New York: Columbia University Press, 2004.

ATLAN, Henri. Entre le cristal et la fumée: essai sur l'organization du vivant. Paris: Éditions du Seuil, 1979.

BIRTWISTLE, Andy. Cinesonica: sounding film and video. Manchester: Manchester University Press, 2010.

CHION, Michel. Film: a sound art. New York: Columbia University Press, 2009. Audio-vision: sound on screen. New York: Columbia University Press, 1994.

EVENS, Aden. Sound ideas: music, machines and experience. Minneapolis: University of Minnesota Press, 2005.

GIDAL, Peter (Ed.). Structural film anthology. London: BFI, 1978.

GUMBRECHT, Hans Ulrich. Production of presence: what meaning cannot convey. Stanford: Stanford University Press, 2004. 
JORDAN, Randolph. Brakhage's silent legacy for sound cinema; rethink the art of hearing through Brakhage's silent filmaking. Offscreen, v. 7, n. 2, Feb. 2003. Disponível em: $<$ http://offscreen.com/view/brakhage3>. Acesso em: 10 out. 2013.

KAHN, Douglas. Noise, water, meat: a history of sound in the arts. Massachusetts: The MIT Press, 1999.

KAPP, Ernst. Principes d'une philosophie de la technique. Paris: J. Vrin, 2007.

KITTLER, Friedrich. Discourse networks - 1800/1900. Stanford: Stanford University Press, 1990.

LEGOFF, Jacques. História e memória. Campinas: UNICAMP, 1990.

MACKENZIE, Donald. Sound recording by the light-valve system. In: COWAN, Lester (Ed.). Recording sound for motion pictures. New York: McGraw-Hill, 1931, p. 84-95.

MARTINS, Hermínio. Experimentum humanum: civilização tecnológica e condição humana. Belo Horizonte: Fino Traço, 2012.

. The metaphysics of information: the power and the glory of machinehood. ResPublica: Revista Lusófona de Ciência Política e Relações Internacionais. I, p. 165-192, Lisboa, 2005. Disponível em: $<$ http://www.herminiomartins.com/the_metaphysics-1.pdf $>$. Acesso em: 01 jun. 2010.

Hegel, Texas e outros ensaios de teoria social. Lisboa: Século XXI, 1996.

REYNOLDS, Simon. Retromania: pop culture's addiction to its own past. New York: Faber and Faber, 2011.

SHANNON, Claude; WEAVER, Warren. The mathematical theory of communication. Champaign: The University of Illinois Press, 1964. 